\title{
Trends of fruit and vegetable availability in neighbourhoods in Albany, NY, USA, 2003-2012
}

\author{
Akiko S Hosler* and Jamie R Kammer \\ Department of Epidemiology and Biostatistics, University at Albany School of Public Health, One University Place, \\ Rensselaer, NY 12144, USA
}

Submitted 18 October 2013: Final revision received 27 January 2014: Accepted 21 February 2014: First published online 31 March 2014

\begin{abstract}
Objective: To investigate a 9-year trend of fresh fruit and vegetable availability and factors associated with the net availability change in two contrasting neighbourhoods.

Design: Longitudinal design. Data were collected in 2003, 2009 and 2012 through in-store observations. Fresh fruit and vegetable availability was presented by weight-adjusted counts of stores having designated varieties per 10000 population.

Setting: A low-income minority neighbourhood and an adjacent middle-income racially mixed neighbourhood in Albany, NY, USA. These neighbourhoods became sites of fresh produce interventions after baseline data were collected. Subjects: A total of 111, 128 and 146 eligible food stores in respective years. Results: Fresh fruit availability (two or more varieties) increased in both neighbourhoods. Inventory expansion of existing stores and the convenience store intervention contributed to the significant increase $(P$ for trend $=0.04)$ of fresh fruit availability in the minority neighbourhood. Although not statistically significant $(P>0.05)$, the availability of two or more dark-coloured fresh vegetables also increased in the mixed neighbourhood, but declined slightly in the minority neighbourhood. The secular (non-intervention) fresh vegetable availability rate ratio by neighbourhood reached 3.0 in $2012(P<0.01)$. The net decline of fresh vegetable availability in the minority neighbourhood was primarily attributed to inventory reduction of existing stores.

Conclusions: Longitudinal observations revealed narrowed neighbourhood disparities of fresh fruit availability and widened gaps of fresh vegetable availability. Inventory shifts of existing stores impacted the net availability change more profoundly than store opening or closing in the minority neighbourhood. Findings support increasing the programme capacity of the convenience store intervention to address the fresh vegetable disparity.
\end{abstract}

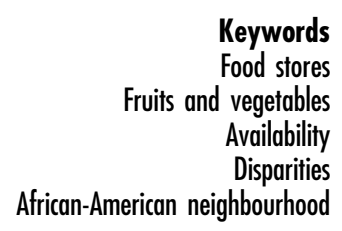

Fruits and vegetables are key components of a healthful, balanced diet, but availability of these vital commodities can be uneven and systematically disadvantage those who are living in socio-economically deprived communities. Research demonstrates that racial minority and low-income neighbourhoods have markedly lower densities of supermarkets and large grocery stores that are likely to have the widest selection of fresh fruits and vegetables, compared with middle-income, non-minority neighbourhoods ${ }^{(1-4)}$. In-store observations confirm that most food stores in disadvantaged neighbourhoods are convenience stores and bodegas, and they offer no or very limited selections of fresh produce ${ }^{(5-8)}$. Instead, processed foods that are energy dense but low in nutritional value occupy much greater shelf space in these small stores ${ }^{(9)}$. Research has also found that availability of retail fresh vegetables is positively associated with consumption of vegetables ${ }^{(10,11)}$. In light of the epidemic of obesity and diet-related chronic diseases, the US Healthy People 2020 includes not only objectives to increase regular consumption of fruits and vegetables, but also objectives to enhance availability of a food retail outlet that sells a variety of healthy foods ${ }^{(12)}$.

Despite the increasing public awareness and scholarly interest, longitudinal research on fruit and vegetable availability has been sparse. Some studies investigated changes of in-store fruit and vegetable availability impacted by a food store intervention ${ }^{(13-15)}$ or a nutrition assistance programme policy change ${ }^{(16-19)}$, but they focused only on short-term changes (6 months to 2 years) using the pre-post measurement design. Long-term secular 
trends of retail fruit and vegetable availability are not well investigated. A research team assessed historic changes (1981-1990) of neighbourhood food environment in four California cities ${ }^{(20)}$. However, that study used published lists of food stores and did not include in-store measurement of fruit and vegetable availability.

As one of few longitudinal, direct observation researches on the food environment, the present study focuses on a 9-year trend (2003-2012) of fresh fruit and vegetable availability in two contrasting neighbourhoods in a northeastern US city. After baseline data collection was completed, these neighbourhoods became sites of ongoing fresh produce interventions by organizations not affiliated with the research team. This turn of events provided an opportunity to assess overall and intervention-impacted changes in the availability. The present study also investigates the roles of store closing, store opening, inventory shifts of existing stores and interventions on the net changes of fruit and vegetable availability.

\section{Methods}

\section{Study setting}

The setting of the present study was an urbanized area consisting of forty-nine contiguous census block groups that make up the downtown portion of Albany, NY, USA. Based on the analysis of the 2000 population census data, the area was divided into a minority neighbourhood (non-White and/or Hispanic population $\geq 50 \%$, twenty-six census block groups) and a racially mixed ('mixed') neighbourhood (non-White and/or Hispanic population $<50 \%$, twenty-three census block groups). The minority neighbourhood closely corresponds to existing historically African-American sections of the city. The minority neighbourhood has significantly higher $(P<0 \cdot 01)$ proportions of individuals living below the federal poverty line $(36 \% v$. 24\%), female-headed households with a minor child $(22 \% v .8 \%)$ and households without a vehicle ( $43 \% v$ v. 30\%) compared with the mixed neighbourhood. Earlier, the research team reported a disproportionately low availability of low-fat milk, high-fibre bread and fresh produce in the minority neighbourhood using baseline cross-sectional data ${ }^{(21,22)}$.

\section{Fresh produce interventions}

In April 2007, a region-wide fresh produce truck intervention targeting low-income residents and seniors was launched by the Capital District Community Gardens (CDCG), a local non-profit organization ${ }^{(23)}$. A refrigerated box truck ('Veggie Mobile') carrying a large variety of wholesale and locally grown fresh fruits and vegetables began making 45- to 80-min weekly stops at designated locations. The study community initially had four stops. In early 2012, with the purchase of a second truck, the number of stops in the study area increased to a total of eight, including two at senior housing complexes in the mixed neighbourhood and six in street corners in the minority neighbourhood.

In February 2011, a new food store intervention was added to the study community. The 'Healthy Convenience Store Initiative' was a collaborative project between the Albany County Department of Health and the CDCG, and supported by a grant from the Centers for Disease Control and Prevention ${ }^{(24)}$. The goal of this initiative was to increase the availability of affordable fresh produce in small independent food stores located in low-income neighbourhoods. Participating stores received an equipment package including a glass refrigeration case, racks, hanging bins and a folding outdoor sign. The CDCG supplied fresh fruits and vegetables at low wholesale prices twice weekly, with a waiver of delivery fee for the first 6 months. The participating stores made profits by selling fresh produce at an affordable retail price. During the initial recruitment period between February and June 2011, three stores joined the intervention, and during the second recruitment period between February and June 2012, four more stores joined from the study community. All of the existing seven stores were located in the minority neighbourhood, and our data indicate that none sold fresh fruits or dark-coloured vegetables in 2009. Three stores were still receiving a delivery fee waiver during the 2012 data collection.

\section{Data collection}

Data were collected from individual food stores in the study community at baseline in 2003 and at two follow-up points in 2009 and 2012, all during summer between late June and early September. Details of the food store identification technique are available elsewhere ${ }^{(25)}$. Briefly, a list of food stores was initially complied by combining several published government administrative databases and a research team systematically canvassed the study area on foot and by car to find additional stores not on the list. A hand-held Geographic Positioning System device was used to measure and record the spatial location of each store.

Eligible food stores for the present study were defined as any retail outlets (year-round or seasonal, stationary or movable, regardless of store business hours) that sold at least one of the following indicator items: milk, bread, fruit or vegetable that is fresh, canned or frozen. This definition was adopted to include any 'non-traditional' food outlets that are becoming increasingly important sources of food supply in low-income minority communities ${ }^{(26)}$. Stores located inside the access-restricted area of an office building were regarded as non-food stores. Each produce truck intervention stop was counted as one store.

A team of two or three trained surveyors assessed the availability (presence) of fresh fruits and vegetables using the in-store food environment assessment tool called Food 
Retail Outlet Survey Tool (FROST). This tool was originally created in 2003 and has been used in food environment studies in urban, rural and ethnic communities ${ }^{(21,22,27,28)}$. Inter-rater reliability was tested with a random sample of stores ( $n$ 39) and had very good overall equivalence (prevalence-adjusted bias-adjusted $\kappa$ of 0.85 or higher for all items) ${ }^{(29)}$. In all data collection years, stores were visited on a random day of the week between 09.00 and 16.00 hours. For the stores participating in the Healthy Convenience Store Initiative, surveyors visited each store twice to adjust for fluctuation of availability caused by the delivery cycle. The University at Albany's Institutional Review Board reviewed and approved the study protocol.

\section{Measurement and data analysis}

As a community-level standardized measure of availability, fresh fruit availability was measured by counts of stores having two or more fresh varieties (except for lemons and limes) per 10000 population. Similarly, fresh vegetable availability was measured by counts of stores having two or more dark-coloured fresh varieties per 10000 population. The definition of dark-coloured vegetables (dark green-, red- or orange-coloured varieties) was based on the US Department of Agriculture's vegetable classification for the Dietary Guidelines for Americans ${ }^{(30)}$. These fruits and vegetable varieties were also considered minimally acceptable selections in a small food store ${ }^{(13)}$. Weights were applied to the availability measure to adjust for store size and store operating hours. Specifically, weights were obtained as 1 plus the natural-log-transformed number of cash registers (a surrogate measure of store size), multiplied by the store hours per week divided by 98 . A constant of 98 was used for stores operating $98 \mathrm{~h} /$ week or longer. Details of weight calculation are discussed elsewhere $^{(22,27)}$.

The $\chi^{2}$ trend analysis was used to evaluate statistically significant changes of overall, intervention-impacted and secular (non-intervention) availability over time in each neighbourhood. The rate ratio between the mixed and minority neighbourhoods was computed to evaluate disparities of availability. The two-tailed $z$ test was used to examine whether the rate ratio was significantly different from the null (rate ratio $=1 \cdot 0$ ). In addition, the net changes in the overall availability that were attributed to store closing/opening, inventory reduction/expansion and interventions were analysed, using the store status information at baseline and 2012. The statistical software package IBM SPSS Statistics for PC version $19 \cdot 0$ was used for the analyses.

\section{Results}

Total numbers of eligible food stores were 111 in 2003, 128 in 2009 and 146 in 2012. All eligible stores granted permission to conduct an in-store survey. As shown in Table 1 , the numbers of stores in the mixed neighbourhood ( $n$ 55, 61 and 67 in respective years) and the minority neighbourhood ( $n$ 56, 67 and 80) were similar, but characteristics of stores were markedly different. The dominant type of stores in the minority neighbourhood was convenience store/bodega and no supermarkets or farmers' markets were located in this neighbourhood. Size of stores was generally small, with only one large store (having four or more cash registers) in 2003 and no large stores in 2009 or 2012. In contrast, the mixed neighbourhood had multiple supermarkets and farmers' markets, and the number of large stores increased from nine in 2003 to sixteen in 2012. Authorized retailers of the Special Supplemental Nutrition Program for Women, Infants, and Children (WIC) increased from three in 2003 to five in 2012 in the mixed neighbourhood, but decreased from six to two in the minority neighbourhood.

Table 1 Food store characteristics by neighbourhood in 2003, 2009 and 2012, Albany, NY, USA

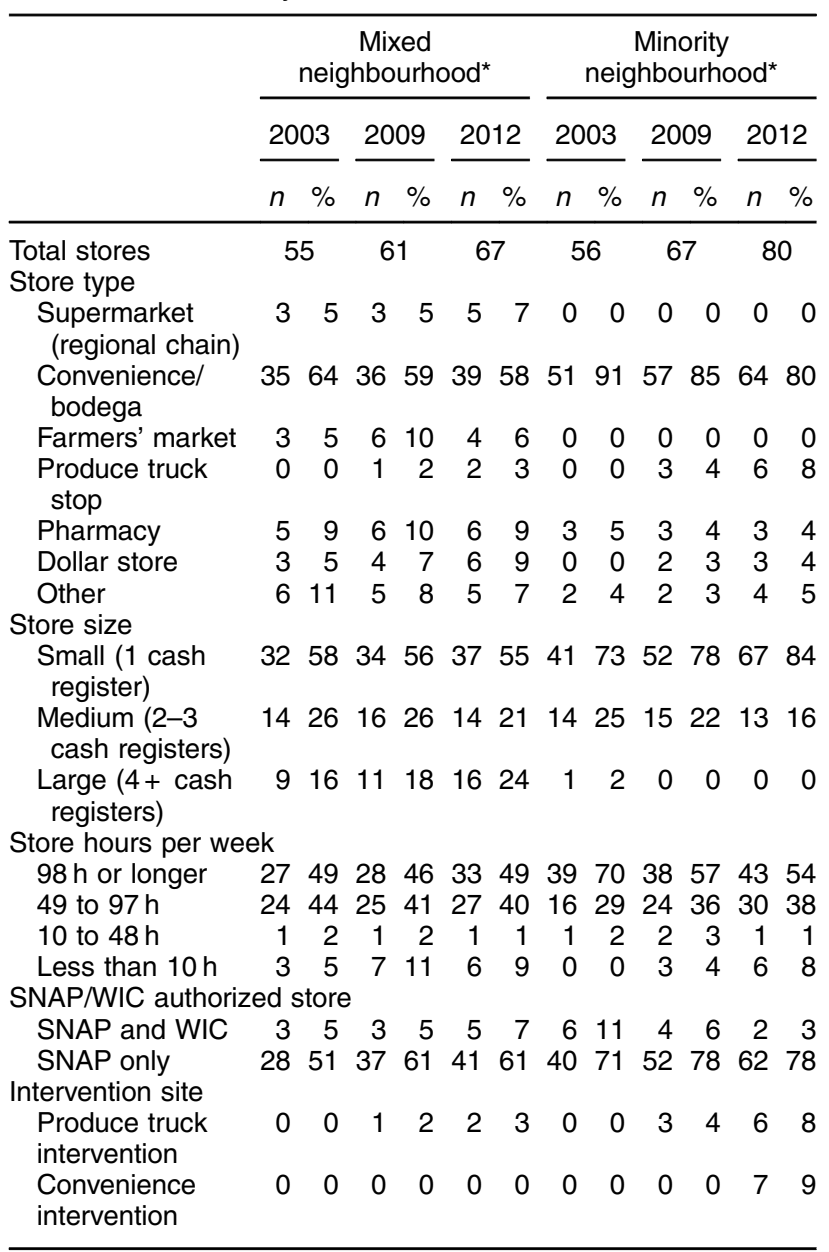

SNAP, Supplemental Nutrition Assistance Program; WIC, Special Supplemental Nutrition Program for Women, Infants, and Children.

*Mixed neighbourhood is defined by census block groups with non-White and/or Hispanic population $<50 \%$; minority neighbourhood is defined by census block groups with non-White and/or Hispanic population $\geq 50 \%$. 
Table 2 depicts that the weight-adjusted overall availability of two or more varieties of fresh fruits increased in the mixed neighbourhood $(8 \cdot 6,11 \cdot 1$ and $12 \cdot 3$ in respective years, $P$ for trend $=0 \cdot 10$ ) as well as in the minority neighbourhood (6.1, 6.7 and 9.9, $P$ for trend=0.04). The overall availability rate ratio for fresh fruits, an indicator of disparity, decreased from 1.6 in 2009 to 1.2 in 2013. The convenience store intervention in the minority neighbourhood (overall availability $=2.4$ in 2012) helped to reduce the fresh fruit disparities. The produce truck intervention had a negligible contribution (overall availability $=<0 \cdot 1$ in 2009 and 2012) in both neighbourhoods.

The availability of two or more dark-coloured fresh vegetables had mixed results. Although not statistically significant, the overall availability increased in the mixed neighbourhood $(7 \cdot 7,8.3$ and 10.3 in respective years, $P$ for trend $=0.23$ ) but decreased slightly in the minority neighbourhood $(5.7,4.5$ and $4.4, P$ for trend $=0.43)$. The secular availability decline of fresh vegetables in the minority neighbourhood was nearly significant ( $P$ for trend $=0.07)$ and the secular rate ratio reached 3.0 in 2012, which was significantly higher $(P<0.01)$ than the null. The contribution of the convenience store intervention (overall availability $=1.0$ in 2012) was not large enough to reduce the disparity. The produce truck intervention again contributed very little to the overall fresh vegetable availability (<0.1 in 2009 and 2012 in both neighbourhoods).

Table 3 provides insights into reasons for overall availability changes during the 9-year period. In the mixed neighbourhood, the net increase in the availability of fresh fruits $(+3.7)$ and fresh vegetables $(+2 \cdot 6)$ were primarily brought about by opening of new food stores carrying respective items $(+3 \cdot 6$ and $+3 \cdot 1)$, coupled with a very small impact of store closing $(-0 \cdot 1$ for both). In the minority neighbourhood, inventory expansion of existing stores $(+3 \cdot 0)$ and the convenience store intervention
$(+2 \cdot 4)$ were two major contributors to the net fresh fruit availability increase $(+3 \cdot 8)$. Inventory reduction of existing stores $(-3 \cdot 6)$ was the largest factor for the net decline of fresh vegetable availability $(-1 \cdot 3)$.

\section{Discussion}

The present longitudinal study revealed the trends of community-level fruit and vegetable availability over a 9-year period in low-income minority and middle-income mixed neighbourhoods in Albany, NY, USA. The narrowing disparity of fresh fruit availability was an encouraging development, but the gradually widening gap of darkcoloured fresh vegetable availability reinforced the notion that nutrient-rich vegetables are becoming increasingly hard to obtain in socio-economically deprived neighbourhoods.

The increased availability of fresh fruits and vegetables in the mixed neighbourhood came mainly from secular, commercial development. In this community of large parking lots and winterized bus stops, addition of several large food stores including two new supermarkets and very few closings of existing produce stores contributed to the steady increase of the availability of fresh fruits and vegetables.

In the minority neighbourhood where no supermarkets or farmers' markets existed, it was the collective behaviour of existing small stores and the support of interventions that largely determined the overall availability. The increase of secular fresh fruit availability appears to be linked to the 'fruits for snack' marketing strategy, where stores offer loose pieces of fresh bananas, apples, oranges and the like as a grab-and-go item. These fresh fruits were strategically placed next to the cash register, near the candy rack or on the deli counter. As shown in Table 4, the unweighted number of non-intervention stores selling at

Table 2 Availability (measured as weight-adjusted counts of stores per 10000 population) of fresh fruits and vegetables by neighbourhood in 2003, 2009 and 2012, Albany, NY, USA

\begin{tabular}{|c|c|c|c|c|c|c|c|c|c|c|c|}
\hline & \multicolumn{3}{|c|}{ Mixed neighbourhood* } & \multirow[b]{2}{*}{$P$ for trend } & \multicolumn{3}{|c|}{ Minority neighbourhood* } & \multirow[b]{2}{*}{$P$ for trend } & \multicolumn{3}{|c|}{ Rate ratio by neighbourhood } \\
\hline & 2003 & 2009 & 2012 & & 2003 & 2009 & 2012 & & 2003 & 2009 & 2012 \\
\hline \multicolumn{12}{|c|}{ Fresh fruits (two or more varieties) $\dagger$} \\
\hline Overall availability & 8.6 & $11 \cdot 1$ & $12 \cdot 3$ & $0 \cdot 10$ & $6 \cdot 1$ & $6 \cdot 7$ & 9.9 & 0.04 & 1.4 & 1.6 & $1 \cdot 2$ \\
\hline No interventions (secular) & 8.6 & $11 \cdot 1$ & $12 \cdot 3$ & $0 \cdot 10$ & $6 \cdot 1$ & $6 \cdot 7$ & 7.5 & 0.41 & 1.4 & $1 \cdot 6$ & 1.6 \\
\hline Produce tuck intervention & $\mathrm{n} / \mathrm{a}$ & $<0.1$ & $<0.1$ & & $\mathrm{n} / \mathrm{a}$ & $<0.1$ & $<0.1$ & & & & \\
\hline Convenience intervention & $\mathrm{n} / \mathrm{a}$ & $\mathrm{n} / \mathrm{a}$ & $\mathrm{n} / \mathrm{a}$ & & $\mathrm{n} / \mathrm{a}$ & $\mathrm{n} / \mathrm{a}$ & $2 \cdot 4$ & & & & \\
\hline \multicolumn{12}{|c|}{ Fresh vegetables (two or more dark varieties) $\ddagger$} \\
\hline Overall availability & $7 \cdot 7$ & 8.3 & $10 \cdot 3$ & 0.23 & 5.7 & 4.5 & 4.4 & 0.43 & 1.3 & 1.9 & $2 \cdot 4$ \\
\hline No intervention (secular) & $7 \cdot 7$ & $8 \cdot 3$ & $10 \cdot 3$ & 0.23 & $5 \cdot 7$ & 4.5 & 3.4 & 0.14 & $1 \cdot 3$ & 1.9 & $3.0 \S$ \\
\hline Produce tuck intervention & $\mathrm{n} / \mathrm{a}$ & $<0.1$ & $<0.1$ & & $\mathrm{n} / \mathrm{a}$ & $<0.1$ & $<0.1$ & & & & \\
\hline Convenience intervention & $\mathrm{n} / \mathrm{a}$ & $\mathrm{n} / \mathrm{a}$ & $\mathrm{n} / \mathrm{a}$ & & $\mathrm{n} / \mathrm{a}$ & $\mathrm{n} / \mathrm{a}$ & 1.0 & & & & \\
\hline
\end{tabular}

n/a, not applicable.

*Mixed neighbourhood is defined by census block groups with non-White and/or Hispanic population $<50 \%$; minority neighbourhood is defined by census block groups with non-White and/or Hispanic population $\geq 50 \%$.

†Excluding lemons and limes.

¥Fresh vegetables that are dark green-, red- or orange-coloured.

$\S$ Significantly $(P<0.01)$ higher than the null $(1 \cdot 00)$. 
Table 3 Reasons for net change of fresh fruit and vegetable availability (measured as weight-adjusted counts of stores per 10000 population), 2003-2012, Albany, NY, USA

\begin{tabular}{|c|c|c|c|c|c|c|}
\hline & \multicolumn{2}{|c|}{ Decreased availability } & \multicolumn{3}{|c|}{ Increased availability } & \multirow[b]{2}{*}{$\begin{array}{l}\text { Net change } \\
2003-2012\end{array}$} \\
\hline & $\begin{array}{l}\text { Store } \\
\text { closing }\end{array}$ & $\begin{array}{l}\text { Inventory } \\
\text { reduction }\end{array}$ & $\begin{array}{l}\text { Store } \\
\text { opening }\end{array}$ & $\begin{array}{l}\text { Inventory } \\
\text { expansion }\end{array}$ & $\begin{array}{l}\text { Convenience } \\
\text { intervention }\end{array}$ & \\
\hline \multicolumn{7}{|c|}{ Fresh fruits (two or more varieties) ${ }^{*}$} \\
\hline $\begin{array}{l}\text { Mixed } \\
\text { neighbourhood } \dagger\end{array}$ & -0.1 & $-1 \cdot 6$ & $+3 \cdot 6$ & $+1 \cdot 8$ & 0 & +3.7 \\
\hline $\begin{array}{l}\text { Minority } \\
\text { neighbourhood } \dagger\end{array}$ & $-1 \cdot 1$ & $-1 \cdot 6$ & $+1 \cdot 1$ & $+3 \cdot 0$ & $+2 \cdot 4$ & $+3 \cdot 8$ \\
\hline \multicolumn{7}{|c|}{ Fresh vegetables (two or more dark varieties) $\ddagger$} \\
\hline $\begin{array}{l}\text { Mixed } \\
\text { neighbourhood } \dagger\end{array}$ & -0.1 & -0.8 & $+3 \cdot 1$ & +0.4 & 0 & $+2 \cdot 6$ \\
\hline $\begin{array}{l}\text { Minority } \\
\text { neighbourhood } \dagger\end{array}$ & $-1 \cdot 4$ & -3.6 & $+1 \cdot 4$ & $+1 \cdot 3$ & $+1 \cdot 0$ & $-1 \cdot 3$ \\
\hline
\end{tabular}

${ }^{*}$ Excluding lemons and limes.

†Mixed neighbourhood is defined by census block groups with non-White and/or Hispanic population $<50 \%$; minority neighbourhood is defined by census block groups with non-White and/or Hispanic population $\geq 50 \%$.

$\ddagger$ Fresh vegetables that are dark green-, red- or orange-coloured.

Table 4 Unweighted counts of non-intervention stores in the minority neighbourhood having specific fruit and vegetable varieties in 2003, 2009 and 2013, Albany, NY, USA

\begin{tabular}{|c|c|c|c|}
\hline & 2003 & 2009 & 2012 \\
\hline Number of non-intervention stores in minority neighbourhood ${ }^{*}$ & 56 & 64 & 67 \\
\hline \multicolumn{4}{|l|}{ Stores carrying fresh fruits } \\
\hline Two or more varieties $\dagger$ & 14 & 16 & 18 \\
\hline One variety only & 4 & 5 & 6 \\
\hline \multicolumn{4}{|l|}{ Three most popular fresh fruit varieties } \\
\hline Bananas & 12 & 18 & 23 \\
\hline Apples & 14 & 14 & 16 \\
\hline Oranges & 13 & 13 & 16 \\
\hline \multicolumn{4}{|l|}{ Stores carrying fresh vegetables } \\
\hline Two or more dark-coloured varieties $\ddagger$ & 13 & 11 & 9 \\
\hline One dark variety and/or light-coloured varieties only & 6 & 16 & 20 \\
\hline \multicolumn{4}{|l|}{ Three most popular fresh vegetable varieties } \\
\hline Onions & 16 & 26 & 29 \\
\hline Potatoes & 13 & 22 & 25 \\
\hline Tomatoes & 13 & 17 & 13 \\
\hline
\end{tabular}

*Minority neighbourhood is defined by census block groups with non-White and/or Hispanic population $\geq 50 \%$.

†Excluding lemons and limes.

${ }^{\ddagger} F$ Fresh vegetables that are dark green-, red- or orange-coloured.

least one variety of fresh fruits increased from eighteen in 2003 to twenty-one in 2009 and twenty-four in 2012 in the minority neighbourhood. This increase also seems to be associated with the growing popularity of bananas, which were the most consumed fresh fruits in the USA in $2010^{(31)}$. Among the non-intervention stores, bananas became the most popular fresh fruits in 2009, and nearly every store with fresh fruits carried bananas in 2012. Only two stores, however, offered bulk fruits (sold by weight or by volume) and/or fruits packaged in a large, family-sized bag.

The decreasing availability of dark-coloured vegetables was impacted by the increasing number of stores skewing their vegetable inventories towards light-coloured varieties such as onions and potatoes that have a relatively long shelf life without refrigeration. In fact, non-intervention stores with only an assortment of light-coloured vegetables and/or one variety of dark-coloured vegetables increased from six in 2003 to sixteen in 2009 and twenty in 2012 in the minority neighbourhood (see Table 4). It was observed that vegetables were often placed in boxes or crates in the back of the store to avoid direct sunlight exposure, but this seemed to be creating low customer exposure and missed sales opportunities.

The two fresh produce interventions had varied outcomes. Previous research found a positive association between the produce truck intervention and vegetable intake among residents of two senior housing complexes located outside the minority neighbourhood ${ }^{(23)}$. The produce truck stops in the minority neighbourhood, however, were at street corners and without defined institutional clients. With its unique direct marketing strategy, the produce truck intervention has established a symbolic presence in the minority neighbourhood, but despite doubling the number of stops, the very short hours of operation (average of $60 \mathrm{~min} /$ week per stop) considerably 
limited its contribution to the community-level fresh fruit and vegetable availability measures. The average operating hours of stationary stores carrying fresh fruits and/or vegetables was $103 \mathrm{~h} /$ week in 2012.

The Healthy Convenience Store Initiative had a more tangible contribution, particularly to the increase of fresh fruit availability in the minority neighbourhood. All seven participating stores had two or more varieties of fresh fruits during two data collection visits, although only three had two or more varieties of dark-coloured vegetables in either of the visits (tomatoes, red bell peppers, yams and butternut squashes were found in these stores). A report of the intervention stores submitted to the county health department in June 2012 included asparagus, broccoli and spinach as additional items sold, but our visits did not capture these particular items. Large green vegetables might sell out quickly, as the quantity of these perishable items each store could carry was constrained by the small size of the refrigeration case, which measured approximately 6 cubic feet.

The results of the present study provide several implications for public health policy and future research. It is apparent that policy and intervention should prioritize increasing the availability of dark-coloured vegetables in the minority neighbourhood and reverse the trend of growing disparities. In the neighbourhood where even a farmers' market has historically very poor presence, policy makers intuitively knew that introduction of a new produce retail store might not be the best solution. There have been attempts to open a scaled-down chain supermarket outlet and a food co-op store in the minority neighbourhood, but none of the plans became reality. The present study empirically demonstrated that existing stores play a major role in the changes of fresh produce availability, and working with the existing small stores to create and maintain a diverse produce inventory would be a workable solution. The convenience store initiative's contribution to the increase of fresh fruit availability can be replicated with dark-coloured vegetables, through providing larger refrigeration equipment and assisting display and marketing strategies. The programme should entice a long-term commitment, to make sure that participating stores do not fall back to only selling onions and potatoes. Continuous longitudinal monitoring of the in-store food environment is necessary to provide a scientific basis of the intervention effort. Additional research on the nutritional knowledge and shopping behaviour of consumers is also needed to understand the demand side of the food environment equation.

Limitations exist in the present study. Except for stores participating in the Healthy Convenience Store Initiative, all stores were visited only once at each data collection wave. Inventory of fruits and vegetables can fluctuate by wholesale delivery schedule, re-shelving cycle or the weather, which may result in misclassification of availability. Quality of fresh fruits and vegetables was not assessed. All data collections occurred in summer months when all farmers' markets were in operation. In colder months when some of the farmers' markets close, the availability of fruits and vegetables would decrease slightly in the mixed neighbourhood. Fresh fruits and vegetables that were prepared for immediate consumption (such as salad bar) were not assessed. The adjustment weights, which have a median of 1.0 and a mean of 1.1 (SD 0.7 ), were devised to provide mathematical adjustments in the community-level store availability calculation, and they should not be applied to store-to-store availability comparisons. The study's narrow focus on specific neighbourhoods can weaken its ability to generalize findings.

Finally, the study did not investigate an impact of the WIC policy change. In October 2009, one month after the completion of the 2009 data collection, all WIC-authorized retailers were required to carry fruits and vegetables following the WIC food package revision. Several studies reported improved in-store fruit and vegetable availability shortly after the policy change ${ }^{(16-19)}$. However, it appears that the study community received little positive impact from the WIC food package revision, largely because the number of WIC retailers had been very small. There were a total of seven WIC retailers in 2009 and 2012. Two independent WIC retailers in the minority neighbourhood lost WIC authorization in 2011 due to a circumstance unrelated to the WIC mandate, while two new supermarkets in the mixed neighbourhood became WIC retailers in 2010 and 2012. The very low density of WIC retailers in the minority neighbourhood ( 1 per 14000 residents in 2012) itself is a major concern and calls for public health policy action.

\section{Conclusion}

In summary, the present study demonstrated that neighbourhood disparities of fresh fruit and vegetable availability persisted over time, but the magnitude and directional trends of the disparities differed by fruits and vegetables. Dark-coloured fresh vegetables were becoming less available in the low-income minority neighbourhood, as stores shifted their inventories towards lightcoloured vegetable varieties only. On the other hand, fresh fruit availability gradually improved in the same neighbourhood, largely through collective adaptation of the marketing strategy to sell popular 'fruits for snack' as well as assistance of the interventions. Findings of the study suggest that increasing the programme capacity of the Healthy Convenience Store Initiative to support the enhancement of fresh vegetable availability would be a feasible approach to address the growing disparity of dark-coloured vegetables.

\section{Acknowledgements}

Acknowledgements: The authors would like to acknowledge the Albany Prevention Research Center staff and the 
School of Public Health student interns and volunteers. Financial support: Financial support for this research was provided by the Centers for Disease Control and Prevention (CDC) Prevention Research Center Grant (U48 CCU220083); the New York State Department of Health Maternal and Child Health Block Grant; and the University at Albany Faculty Research Program Award. The CDC, the New York State Department of Health and the University at Albany had no role in the design, analysis or writing of this article. Conflict of interest: None. Authorship: A.S.H. conceived the study, supervised and conducted data collection, conducted data analysis and wrote the manuscript. J.R.K. conducted data collection, assisted data analysis and provided comments on the manuscript. Ethics of buman subject participation: The University at Albany Institutional Review Board reviewed and approved the protocol of this research.

\section{References}

1. Alwitt LF \& Donley TD (1997) Retail stores in poor urban neighbourhoods. J Consum Aff 31, 139-164.

2. Moore LV \& Diez Roux AV (2006) Associations of neighbourhood characteristics with the location and type of food stores. Am J Public Health 96, 325-331.

3. Powell LM, Slater S \& Mirtcheva D et al. (2007) Food store availability and neighbourhood characteristics in the United States. Prev Med 44, 189-195.

4. Morland K, Wing S \& Diez Roux A et al. (2002) Neighborhood characteristic as associated with the location of food stores and food service places. Am J Prev Med 22, 23-29.

5. Horowitz CR, Colson KA \& Hebert PL et al. (2004) Barriers to buying healthy foods for people with diabetes: evidence of environmental disparities. Am J Public Health 94, 1549-1554.

6. Block D \& Kouba J (2006) A comparison of the availability and affordability of a market basket in two communities in the Chicago area. Public Health Nutr 9, 837-845.

7. Morland K \& Filomena S (2007) Disparities in the availability of fruits and vegetables between racially segregated urban neighbourhoods. Public Health Nutr 10, 1481-1489.

8. Franco M, Diez Roux AV \& Glass TA et al. (2008) Neighborhood characteristics and avaiablity of healthy foods in Baltimore. Am J Prev Med 35, 561-567.

9. Bodor JN, Rice JC \& Farley TA et al. (2010) Disparities in food access: does aggregate availability of key foods from other stores offset the relative lack of supermarkets in African-American neighbourhoods? Prev Med 51, 63-67.

10. Bodor JN, Rose D \& Farley TA et al. (2008) Neighbourhood fruit and vegetable availability and consumption: the role of small food stores in an urban environment. Public Health Nutr 11, 413-420.

11. Izumi BT, Zenk SN \& Schultz AJ et al. (2011) Associations between neighborhood availability and individual consumption of dark-green and orange vegetables among ethnically diverse adults in Detroit. J Am Diet Assoc 111, 274-279.

12. US Department of Health and Human Services, Office of Disease Prevention and Health Promotion (2010) Healthy People 2020. Washington, DC: US DHHS; available at http://www.healthypeople.gov/2020/topicsobjectives2020/ objectiveslist.aspx?topicId $=29$

13. Dannefer R, Williams DA \& Baronberg S et al. (2012) Healthy bodegas: increasing and promoting healthy foods at corner stores in New York City. Am J Public Health 102, e27-e31.

14. Hartford Food System (2008) One Year Later: An Inspection of Hartford Stores Shows Measurable Progress for the Healthy Food Retailer Initiative. Hartford, CT: Harford Food System; available at http://www.hartfordfood.org/ publications/healthy_retailers08.pdf

15. Food Trust (2012) Philadelphia's Healthy Corner Store Initiative 2010-2012. Philadelphia, PA: Food Trust; available at http://thefoodtrust.org/uploads/media_items/ hcsi-y2report-final.original.pdf.

16. Andreyeva T, Luedicke J \& Middleton AE et al. (2012) Positive influence of the revised Special Supplemental Nutrition Program for Women, Infants, and Children food packages on access to healthy foods. J Acad Nutr Diet 112, $850-858$.

17. Hillier A, McLaughlin J \& Cannuscio CC et al. (2012) The impact of WIC food package changes on access to healthful food in 2 low-income urban neighborhoods. $J$ Nutr Educ Behav 44, 210-216.

18. Havens EK, Martin KS \& Yan J et al. (2012) Federal nutrition program changes and healthy food availability. Am J Prev Med 43, 419-422.

19. Zenk SN, Odoms-Young A \& Powell LM et al. (2012) Fruit and vegetable availability and selection: federal food package revisions, 2009. Am J Prev Med 43, 423-428.

20. Wang MC, Cubbin C \& Ahn D et al. (2008) Changes in neighbourhood food store environment, food behaviour and body mass index, 1981-1990. Public Health Nutr 11, 963-970.

21. Hosler AS, Varadarajulu D \& Ronsani AE et al. (2006) Lowfat milk and high-fiber bread availability in food stores in urban and rural communities. J Public Health Manag Pract 12, 556-562.

22. Hosler AS, Rajulu D \& Fredrick BL et al. (2008) Assessing retail fruit and vegetable availability in urban and rural underserved communities. Prev Chronic Dis 5, A123.

23. Abusabha R, Namjoshi D \& Klein A (2011) Increasing access and affordability of produce improves perceived consumption of vegetables in low-income seniors. J Am Diet Assoc 111, 1549-1555.

24. Empire State News (2012) Albany County Health Program Gets National Award. Albany, NY: Empire State News; available at http://www.empirestatenews.net/News/ 20120720-5.html

25. Hosler AS \& Dharssi A (2011) Identifying retail food stores to evaluate the food environment. Am J Prev Med 39, 41-44.

26. Odoms-Young AM, Zenk S \& Mason M (2009) Measuring food availability and access in African-American communities: implications for intervention and policy. Am J Prev Med 36, 4 Suppl., S145-S150.

27. Hosler AS (2009) Retail food availability, obesity, and cigarette smoking in rural communities. J Rural Health 25, 202-209.

28. Lopez-Class M \& Hosler AS (2010) Assessment of community food resources: a Latino neighbourhood study in upstate New York. J Poverty 14, 369-381.

29. Hosler AS \& Dharssi A (2011) Reliability of a survey tool for measuring consumer nutrition environment in urban food stores. J Public Health Manag Pract 17, E1-E8.

30. US Department of Agriculture (2011) What Foods Are in the Vegetable Group. http://www.choosemyplate.gov/foodgroups/vegetables.html (accessed December 2013).

31. US Department of Agriculture, Economic Research Service (2012) Most Commonly Consumed Fresh Fruits Among US Consumers. http://www.ers.usda.gov/data-products/chartgallery/detail.aspx?chartId=30486\#.UtmhkxAo7cs (accessed December 2013). 